\title{
The Ugly Side of Statins. Systemic Appraisal of the Contemporary Un-Known Unknowns
}

\author{
Sherif Sultan ${ }^{1,2 \#}$, Niamh Hynes ${ }^{1,2}$ \\ ${ }^{1}$ Department of Vascular and Endovascular Surgery, Western Vascular Institute, \\ University College Hospital Galway, Galway, Ireland \\ ${ }^{2}$ Department of Vascular and Endovascular Surgery, Galway Clinic, Galway, Ireland \\ Email: " sherif.sultan@hse.ie
}

Received April 11, 2013; revised May 12, 2013; accepted June 12, 2013

Copyright (c) 2013 Sherif Sultan, Niamh Hynes. This is an open access article distributed under the Creative Commons Attribution License, which permits unrestricted use, distribution, and reproduction in any medium, provided the original work is properly cited.

\begin{abstract}
Cardio-vascular specialists have witnessed and actively participated in the revolutionary developments that have occurred in their field of specialization over the last few years. Cutting-edge technologies have led to dramatic improvements in life-expectancy and quality of life. An open-mind and pioneering attitude are necessary when exploring new frontiers to improve our patients' health. However, naïve indiscriminate acceptance of novel mainstream therapies is not always advisable and prudence is required in unearthing harmful, covert side effects. An objective review of contemporary vascular research was performed and industrial bias was sifted out for a fresh prospective on how to promote primary cardiovascular prevention with attainable lifestyle adjustments [1]. A comprehensive review of Pubmed, EMBASE and Cochrane review databases was undertaken for articles relating to cardiovascular primary prevention and statin side effects with the aim of harmonising their roles within contemporary clinic practice. Particular attention was paid to large-scale randomised controlled trials on contemporary cardiovascular pharmacotherapies and their specific adverse effects on metabolic pathways which feature prominently in cardiovascular primary prevention and regenerative programmes. There is a categorical lack of clinical evidence to support the use of statin therapy in primary prevention. Not only is there a dearth of evidence for primary cardiovascular protection, there is ample evidence to show that statins actually augment cardiovascular risk in women, patients with Diabetes Mellitus and in the young. Furthermore statins are associated with triple the risk of coronary artery and aortic artery calcification. Cardiovascular primary prevention and regeneration programmes, through life style changes and abstaining from tobacco use have enhanced clinical efficacy and quality of life over any pharmaceutical or other conventional intervention.
\end{abstract}

Keywords: Statin; Primary Prevention; Side-Effects; Diabetes Mellitus

\section{Introduction}

The endovascular revolution has brought about unprecedented changes in our cardiovascular practice over the last twenty five years. In the course of this insurgence, we contemplated that gene therapy would supplant all technologies. However, after phase three human gene trials and more than three billion euro squandered globally on research and development, all that we have attained is the realisation that we are remote from any ground breaking clinical outcome. Equally the new kid

\footnotetext{
*Neither author has any conflict of interest The authors declare no support from any organisation for the submitted work; no financial relationships with any organisations that might have an interest in the submitted work, no other relationships or activities that could appear to have influenced the submitted work.

${ }^{\#}$ Corresponding author.
}

on the block, allogenic cultured stem cell therapy has failed to deliver; its benefits are short lived, it is costly to set up and we are a decade away from human relevance.

Cardiovascular disease is projected to turn into the predominant cause of death and incapacity worldwide. However, evidence advocates that the atherosclerotic process can be decelerated and its consequences decreased by preventive measures. Primary prevention usually refers to healthy lifestyle choices to prevent the development of coronary risk factors [2].

It is beginning to dawn on some clinicians that contemporary treatments are not only failing to impact on our most prevalent diseases, but they may be causing more damage than good. A perfect example of such an issue is the statin saga.

In excess of 55 trials on statin therapy have been un- 
dertaken with some trial periods spanning 12 years and these drugs have been piloted in several countries over the course of four decades. However, despite hopes of finding a wonder drug which would significantly reduce cardiovascular risk, the results elicited that there was no intervention that resulted in any significant reductions in risk factors, mainly blood pressure, and cholesterol and in terms of primary prevention there has been little or no impact on the risk of CHD mortality or morbidity [2].

The finding in a Cochrane systemic review by Taylor et al. is alarming [3]. They reviewed the current concept of the use of statins in primary prevention and found evidence of selective reporting of outcomes, failure to report adverse events and inclusion of people with cardiovascular disease. Only limited evidence showed that primary prevention with statins may be cost effective and improve patient quality of life. The authors cautioned about prescribing statins for primary prevention among people at low cardiovascular risk.

Although there is no evidence for statin therapy for primary prevention, it must be stressed that current statin guidelines give evidence for the use of statin for secondary prevention. The results of contemporary trials in cardiovascular medicine have challenged current practice, and have forced physicians to do a u-turn on their primary prevention practices [4]. What this highlights is the need for repeated guideline appraisals and revisions and the need for skillful clinical judgment [1].

\section{Methods}

We performed a comprehensive review of Pubmed, EMBASE and Cochrane review databases for articles relating to cardiovascular primary prevention, statin side effects, and pharmacotherapies with the aim of harmonising their roles within contemporary clinic practice. We searched in particular for large-scale randomised controlled trials on contemporary cardiovascular pharmacotherapies and their specific adverse effects on metabolic pathways which feature prominently in cardiovascular programmes.

Search Terms included "Cardiovascular Disease" and each of the following terms separately, Primary Prevention, Statin Therapy, statin side effects, Cataract, Parkinson disease, Rhabdomyolisis, Erectile dysfunction, Peripheral neuritis, Memory loss, amnesia, Muscle Fatigue, Squamous cell Carcinoma, Cancer, Intra cerbral bleed, Coronary artery calcification.

We selectively reviewed the literature, give precedence to clinical reviews, meta-analysis and large-scale randomised controlled trials. We broadly discussed the topic of statin therapy, to incorporate all research findings on the use of statin therapy for cardiovascular disease prevention, paying particular attention to possible side-effects. The main areas we addressed and the most prominent papers relating to these areas are outlined in Table 1.

\section{Review of the Statin Saga}

Cholesterol is crucial for energy, immunity, fat metabolism, leptin, thyroid hormone activity, liver related synthesis, stress intolerance, adrenal function, sex hormone syntheses and brain function. When prescribing HMGCoA reductase inhibitors one needs to be cognisant of the fact that the body had increased its' cholesterol as a compensatory mechanism and investigate accordingly.

We seem to have fallen into the marketing trap and ignored the niggling side effects with regard to the HMGCoA reductase inhibitors [1]. The only statin benefit that has actually been demonstrated is in middle aged men with coronary heart disease. However, statins were not shown to best form of primary prevention. Aspirin, as a form of primary prevention decreases the risk for total cardiovascular events and nonfatal Myocardial Infarction over any other factor [5]. In actual fact, high cholesterol levels have been found to be protective in elderly and heart failure patients and hypo-cholestereamic patients had higher incidence of intra-cerebral bleeds, depression and cancer [1].

The statin industry, with all of its spin-off, is a 20-billion-a-year industry. We are observing the revealing of the utmost medical tragedy of all times. It is unprecedented that the healthcare industry has inadvertently induced life-threatening nutrient deficiency in millions of otherwise healthy people. What is even more disparaging is that not only has there been a failure to report on these negative side-effects of statins, there has actually been active discouragement to publish any negative studies on statins.

For normal healthy individuals who are eager to achieve primary prevention, we discovered that for every 10,000 people taking a statin, there were 307 extra patients with cataracts, 23 additional patients with acute kidney failure and 74 extra patients with liver dysfunction [6-8]. Furthermore, statin therapy increased muscle fatigabilty by $30 \%[9,10]$ with $11.3 \%$ incidence of rhabdomyolysis at high doses. What's more, it induces inflammatory myopathy, including necrotizing autoimmune myopathy with immunosuppression and the statin-related myopathy can last for 12 months.

An additional side-effect of statin therapy is erectile dysfunction, which is 10 times more in young men taking the lowest dose of statin. When statins were discontinued over 50 percent had full recovery within 6 months. Further still the FDA-Adverse reporting system database reported that for every 10,000 reports of a statin-associated adverse event, approximately 40 reports were for 
Table 1. Chosen papers for clinical review.

\section{Primary Prevention}

1 Ebrahim S, Taylor F, Ward K, Beswick A, Burke M, Davey Smith G. Multiple risk factor interventions for primary prevention of coronary heart disease. Cochrane Database Syst Rev. 2011; CD001561.

Taylor F, Ward K, Moore TH, Burke M, Davey Smith G, Casas JP, Ebrahim S. Statins for the primary prevention of cardiovascular disease. Cochrane Database Syst Rev. 2011; 19(1): CD004816.

3 Ray KK, Seshasai SR, Erqou S, Sever P, Jukema JW, Ford I, Sattar N. Statins and all-cause mortality in high-risk primary prevention: A meta-analysis of 11 randomized controlled trials involving 65,229 participants. Arch Intern Med. 2010; 170(12): 1024-1031.

4 Sever PS, Chang CL, Gupta AK, Whitehouse A, Poulter NR; ASCOT Investigators. The Anglo-Scandinavian Cardiac Outcomes Trial: 11-year mortality follow-up of the lipid-lowering arm in the U.K. Eur Heart J. 2011; 32(20): 2525-2532

\section{Statins and Myopathy}

5 El-Salem K, Ababneh B, Rudnicki S, Malkawi A, Alrefai A, Khader Y, Saadeh R, Saydam M. Prevalence and risk factors of muscle complications secondary to statins. Muscle Nerve. 2011; 44: 877-881.

Fernandez G, Spatz ES, Jablecki C, Phillips PS. Statin myopathy: A common dilemma not reflected in clinical trials. Cleve Clin J Med. 2011; 78(6): 393-403

\section{Statins and Lung Disease}

7 Fernandez AB, Karas RH, Alsheikh-Ali AA, Thompson PD. Statins and interstitial lung disease. A systematic review of the Literature and of Food and Drug Administration Adverse Event Reports. Chest. 2008; 134: 824-830

\section{Statins in Women}

Culver AL, Ockene IS, Balasubramanian R, Olendzki BC, Sepavich DM, Wactawski-Wende J, Manson JE, Qiao Y, Liu S, Merriam

8 PA, Rahilly-Tierny C, Thomas F, Berger JS, Ockene JK, Curb JD, Ma Y. Statin use and risk of diabetes mellitus in postmenopausal women in the women's health initiative. Arch Intern Med. 2012; 172(2): 144-152.

9 Rosenberg H, Allard D. Evidence for caution: Women and statin use Women and Health Protection Canadian government white paper, June 2007

\section{Statins and Diabetes}

10 de Lorgeril M, Salen P, Abramson J, Dodin S, Hamazaki T, Kostucki W, Okuyama H, Pavy B, Rabaeus M. Cholesterol lowering, cardiovascular diseases, and the rosuvastatin-JUPITER controversy: A critical reappraisal. Arch Intern Med. 2010; 170(12): $1032-1036$.

Sattar N, Preiss D, Murray HM, Welsh P, Buckley BM, de Craen AJ, Seshasai SR, McMurray JJ, Freeman DJ, Jukema JW, Macfarlane PW, Packard CJ, Stott DJ, Westendorp RG, Shepherd J, Davis BR, Pressel SL, Marchioli R, Marfisi RM, Maggioni AP, Tavazzi L,

11 Tognoni G, Kjekshus J, Pedersen TR, Cook TJ, Gotto AM, Clearfield MB, Downs JR, Nakamura H, Ohashi Y, Mizuno K, Ray KK, Ford I. Statins and risk of incident diabetes: A collaborative meta-analysis of randomised statin trials. Lancet. 2010; 375(9716): 735-742.

\section{Statins and Intracerebral Haemorrrhage}

12 Westover MB, Bianchi MT, Eckman MH, Greenberg SM. Statin use following intracerebral hemorrhage: A decision analysis. Arch Neurol. 2011; 68(5): 573-579

Statins and Parkinson's Disease

13 Lieberman A, Lyons K, Levine J, Myerburg R. Statins, cholesterol, Co-enzyme Q10, and Parkinson’s disease. Parkinsonism Relat Disord. 2005; 11(2): 81-84

\section{Statins and Cancer}

14 Kuoppala J, Lamminpää A, Pukkala E. Statins and cancer: A systematic review and meta-analysis. Eur J Cancer. 2008; 44: $2122-2132$.

\section{Statins and Cataract}

15 Machan CM, Hrynchak PK, Irving EL. Age-related cataract is associated with type 2 diabetes and statin use. Optom Vis Sci. 2012; 89: 1165-1171.

\section{Statins and Arterial Calcification}

Nakazato R, Gransar H, Berman DS, Cheng VY, Lin FY, Achenbach S, Al-Mallah M, Budoff MJ, Cademartiri F, Callister TQ, 6 Chang HJ, Cury RC, Chinnaiyan K, Chow BJW, Delago A, Hadamitzky M, Hausleiter J, Kaufmann P, Maffei E, Raff G, Shaw 6 LJ, Villines TC, Dunning A, Feuchtner G, Kim YJ, Leipsic J, Mina JK. Statins use and coronary artery plaque composition: Results from the International Multicenter Confirm Registry. Atherosclerosis. 2012; 225(1): 148-153.

17 Saremi R, Reaven PD, Bahn G, for the VADT Investigators. Progression of vascular calcification is increased with statin use in the Veterans Affairs Diabetes Trial (VADT). Diabetes Care. 2012; 35: 2390-2392. 
statin-induced interstitial lung disease [11].

All such major adverse clinical events had been reported so frequently, that it prompts authorities to warn of such devastating complications in other wise normal healthy individual, but even when aware of these complications there has been hesitation in putting statin off the market [1].

The US Veterans affair healthcare system study on 15 million veterans in 10 hospitals in Southern USA concluded that statins affect fasting and postprandial glucose level by inducing a state of hyperglycaemia in diabetic as well as non diabetic patients [12]. This relationship between statin use and rise in glucose level is independent of age and use of aspirin, beta blockers and angiotensinconverting enzyme inhibitors. Furthermore, a sub-analysis of the JUPITER study showed that statin therapy can induce full blown type 2 diabetes in women [13].

This was astonishingly shown in the substudy of PROVE-IT TIMI 22, in which there was a significant increased risk of developing HBA1c $>6 \%$ in both diabetics and non diabetics [14]. Moreover Huptas et al. have demonstrated that statin-therapy can induce a state of insulin resistance [15].

The most recent study from the Womens Inititative investigated 153840 post-menopausal women without Diabetes Mellitus [16]. There were 10,242 incident cases of self-reported Diabetes Mellitus over 1,004,466 person-years of follow-up. Statin use at baseline was associated with an increased risk of Diabetes Mellitus and this association remained after adjusting for other potential confounders and was observed for all types of statin medications. The authors concluded that the increased risk for Diabetes Mellitus in postmenopausal women is a medication class effect of statins.

Statins manipulate glucose metabolism as a consequence of inhibitory effects on adipocytes. They induce insulin resistance through reduction in insulin-stimulated glucose uptake with a strong impact on glycaemic control in non obese patients. The poise of use of statins and clear upshot is dogged by the patient metabolic conditions and whether statins could amend or impair insulin resistance and ultimately Type 2 Diabetes Mellitus.

Critical Reappraisal of Cholesterol Lowering therapy in prevention of Cardiovascular Diseases "JUPITER trial” elucidates that the results of trials do not support the use of statin treatment for primary prevention of cardiovascular diseases and raises troubling questions concerning the role of commercial sponsors [17].

Prescribing a statin in old age has a 9\% increase in risk of developing diabetes mellitus [18]. It is another iatrogenic risk factor that must be avoided and it is mandatory to add glucose to the list required for monitoring patients on statin and is equally important as liver-function tests and creatine kinase.
Preiss et al. [19] demonstrated, in a pooled analysis of data from the five major statin trials, an increased incidence of new onset diabetes with statin therapy and provided evidence of a dose dependent association. Furthermore the meta-analysis predicted an $11.3 \%$ enhanced risk of rhabdomyolysis with utilization of high-dose statin therapy.

However, clinical studies and large scale randomized controlled trials demonstrated differences between individual statins, with pravastatin tending to reduce risk of new onset of diabetes while atorvastatin, rosuvastatin and simvastatin together significantly increasing such risk [20].

Objective re-evaluation of trials on the use of statins in secondary stroke prevention [21], such as the SPARCL trial [22], has presented evidence for the avoidance of statin therapy post-stroke in order to avoid intra-cerebral haemorrhage. Moreover a meta-analysis of 11 Randomized Controlled Trials involving 65,229 Participants, conducted to investigate the relationship between statins and all cause mortality in high-risk primary prevention, did not find any evidence for the benefit of statin therapy on all-cause mortality prevention [23].

Parkinson disease and ataxia like syndrome are increasing in nature in a subcategory of old patients. Cholesterol is a critical component of neuronal cell membranes and synapses, and plays an important role in their proper functioning. A strong association between lower cholesterol and Parkinson disease risk has been reported, such that each $\mathrm{mmol} / \mathrm{L}$ increase in total cholesterol was accompanied by a $23 \%$ decrease in the risk of developing Parkinson disease. The risk reduction was significant in women but not in men [24].

Cholesterol levels are the main determinant of coenzyme Q10, an important antioxidant and mitochondrial electron receptor [25]. Coenzyme Q10 is neuroprotective and in study involving patients with early Parkinson disease, administration of high-dosage (1200 mg/day) coenzyme Q10 significantly slowed progression of disability with halting of their statin [26].

Furthermore, evidence exists for an association between the use of statin therapy in patients' post-kidney transplant and enhanced risk of development of squamous cell carcinoma [27]. One systematic review found moderate evidence that statin therapy increased risk of non-melanoma skin cancers (median risk ratio 1.6, range 1.2 - 2.2) [28]. For unknown reasons, since these publications the squamous cell carcinoma has been excluded in all reports from subsequent statin trials.

Rosenberg et al. [29] in a government report to the Canadian authority realised that expectations for the use of statin have not been met. Instead they have found a pattern of overestimation of benefit and underestimation of harm. 
Statins, if used, should only be administered on a short-term basis. This acute benefit is borne out by the fact that despite compliance rates of as low as, $25 \%$ in some cases, after 9 months, from most of the trials we can see that despite cross-overs or poor compliance that once a patient has an initial treatment their benefit remains even if they stopped taking the statin. What's more is that from the ASCOT trial we can see that the greatest survival benefit came from non-cardiovascular deaths seemingly because of the anti-inflammatory effects which reduced deaths from respiratory and infectious causes [30]. If statin therapy is used judiciously in the appropriate patient cohort, and stopped before adverse effects develop, they may have a limited role to play, but only in the short-term.

Vinogradova et al. documented that long term statin use was associated with an increased risk of colorectal cancer, bladder cancer and lung cancer [8].

Another worrying correlation has been unearthed between statin use and premature onset of cataract. There might be an explanation to the sudden rise of number of cataracts in middle-aged men. There is a $50 \%$ probability of cataract development in statin users at earlier age then non-statin users, who develop them at a significantly later age [31].

The Confirm registry had shocked the scientific world with the strongest evidence that statin use is associated with an increased prevalence and extent of coronary plaques calcification [32]. Ironically for a drug which was marketed to lower the risk of cardiovascular disease, the confirm registry identified a strong association of statin use to the progression of coronary artery plaque features.

Moreover, Statin use was correlated with a greater incidence of severe coronary artery stenosis as well as increase in the numbers of coronary vessels developing obstructive coronary artery disease. Furthermore, statin use was linked to an increase in the prevalence and extent of mixed calcific plaque. Five prospective studies have borne witness to the fact that statin therapy does not induce any coronary calcium regression and evolution of coronary calcium continues regardless of statin treatment $[33,34]$.

The Veteran Affairs Diabetes Trial [35] established that statin consumption was linked to accelerated progression of Coronary Artery Calcification (CAC) in participants with Type 2 Diabetes Mellitus without previous coronary artery disease, despite the fact that statin users had significantly lower and nearly optimal LDL-cholesterol levels.

The pathophysiology of this astonishing phenomena of statin-use and increased arterial calcification has been attributed to calcification of vascular smooth muscle cells and mesenchymal cells. Statins lower the lipid-rich core of atherosclerotic plaques and enhance the density of calcification as part of a healing process. This leads to accelerated progression of calcified atherosclerosis in patients with Type 2 Diabetes Mellitus who are taking statins, thereby lessening these medications' overall benefit [35]. This had changed our whole concept about risk benefit considering current statin agents promote calcification in patients with Type 2 Diabetes Mellitus with advanced atherosclerosis.

Randomized controlled trials in largely non-diabetic populations with no previous coronary artery disease demonstrated that, despite potent lipid-lowering effects, statin agents do not reduce the progression of CAC [36] or aortic calcification [37].

Statin therapy activates Atrogen-1 Gene which results in muscle atrophy, wasting and damage. Moreover, statin induced cardiomyopathy is the result of statin-induced coenzyme q10 deficiency and statin-induced atrogen-1 activation [38].

Another warning as to why we should be very prudent about tampering with the body's innate lipid control mechanisms, and one of the best kept secrets in the pharmaceutical industry, is the stopped trial, "the ILLUMINATE trial". This trial was undertaken to investigate a drug that increases HDLbut the investigators found that the drug actually resulted in an increased risk of mortality and morbidity with high cancer rate and sudden death [39].

Patients always ask, "How Long Should I Take a Statin?" It is simply, that if you are at high risk of heart disease or stroke and you take a statin for 30 years, you're likely to live an extra nine months.

\section{Conclusions}

There is increased risk of Diabetes Mellitus, Cataract formation, and Erectile Dysfunction in young statin users, all of which are Alarming. Furthermore there is a significant increase in the risk of cancer and neurodegenerative disorders in the elderly plus an enhanced risk of a myriad of infectious diseases.

All side effects are dose dependant and persist during treatment [1].

Primary prevention clinical results provoke the possibility of not only the lack of primary cardiovascular protection by statin therapy but highlight the very real possibility of augmented cardiovascular risk in women, patients with Diabetes Mellitus and the young . Statins are associated with triple the risk of coronary artery and aortic calcification. These finding on statin major adverse effects had been under-reported and the way in which they withheld from the public, and even concealed, is a scientific farce. 


\section{REFERENCES}

[1] S. Sultan and N. Hynes, "Cardiovascular Disease: Primary Prevention, Disease Modulation and Regenerative Therapy,” Vascular, Vol. 20, No. 5, 2012, pp. 243-250. doi:10.1258/vasc.2012.ra0062

[2] S. Ebrahim, F. Taylor, K. Ward, A. Beswick, M. Burke and G. Davey, "Smith Multiple Risk Factor Interventions for Primary Prevention of Coronary Heart Disease," Cochrane Database of Systematic Reviews, Vol. 19, 2011, Article ID: CD001561. doi:10.1002/14651858.CD001561.pub3

[3] F. Taylor, K. Ward, T. H. Moore, M. Burke, G. Davey Smith, J. P. Casas and S. Ebrahim, "Statins for the Primary Prevention of Cardiovascular Disease," Cochrane Database of Systematic Reviews, Vol. 19, No. 1, 2011, Article ID: CD004816. doi:10.1002/14651858.CD004816.pub4

[4] V. Prasad and A. Vandross, "Cardiovascular Primary Prevention: How High Should We Set the Bar?” Archives of Internal Medicine, Vol. 172, No. 8, 2012, pp. 656-659. doi:10.1001/archinternmed.2012.812

[5] A. A. Bartolucci, M. Tendera and G. Howard, "MetaAnalysis of Multiple Primary Prevention Trials of Cardiovascular Events Using Aspirin,” American Journal of Cardiology, Vol. 107, No. 12, 2011, pp. 1796-1801. doi:10.1016/j.amjcard.2011.02.325

[6] J. Hippisley-Cox and C. Coupland, "Unintended Effects of Statins in Men and Women in England and Wales: Population Based Cohort Study Using the Q Research Database,” British Medical Journal, Vol. 340, 2010, Article ID: c2197.

[7] K. El-Salem, B. Ababneh, S. Rudnicki, A. Malkawi, A. Alrefai, Y. Khader, R. Saadeh and M. Saydam, "Prevalence and Risk Factors of Muscle Complications Secondary to Statins,” Muscle Nerve, Vol. 44, No. 6, 2011, pp. 877-881. doi:10.1002/mus.22205

[8] Y. Vinogradova, C. Coupland and J. Hippisley-Cox, “Exposure to Statins and Risk of Common Cancers: A Series of Nested Case-Control Studies,” BMC Cancer, Vol. 11, No. 1, 2011, p. 409. doi:10.1186/1471-2407-11-409

[9] B. A. Parker, A. L. Augeri, J. A. Capizzi, K. D. Ballard, C. Troyanos, A. L. Baggish, P. A. D’Hemecourt and P. D. Thompson, "Effect of Statins on Creatine Kinase Levels before and after a Marathon Run,” American Journal of Cardiology, Vol. 109, No. 2, 2012, pp. 282-287. doi:10.1016/j.amjcard.2011.08.045

[10] G. Fernandez, E. S. Spatz, C. Jablecki and P. S. Phillips, "Statin Myopathy: A Common Dilemma Not Reflected in Clinical Trials," Cleveland Clinic Journal of Medicine, Vol. 78, No. 6, 2011, pp. 393-403.

[11] A. B. Fernandez, R. H. Karas, A. A. Alsheikh-Ali and P. D. Thompson, "Statins and Interstitial Lung Disease. A Systematic Review of the Literature and of Food and Drug Administration Adverse Event Reports,” Chest, Vol. 134, No. 4, 2008, pp. 824-830. doi:10.1378/chest.08-0943

[12] R. Sukhija, S. Prayaga, M. Marashdeh, Z. Bursac, P. Kakar, D. Bansal, R. Sachdeva, S. H. Kesan and J. L. Mehta, "Effect of Statins on Fasting Plasma Glucose in
Diabetic and Nondiabetic Patients,” Journal of Investigative Medicine, Vol. 57, No. 3, 2009, pp. 495-499.

[13] "Jupiter Subanalysis Rosuvastatin for Cardiovascular Prevention: Too Many Uncertainties,” Prescrire International, Vol. 18, No. 102, 2009, p. 176.

[14] S. Ahmed, C. P. Cannon, S. A. Murohy and E. Braunwald, "Acute Coronary Syndromes and Diabetes: Is Intensive Lipid Lowering Beneficial? Results of the PROVE ITTIMI 22 Trial,” European Heart Journal, Vol. 27, No. 19, 2006, pp. 2323-2329. doi:10.1093/eurheartj/ehl220

[15] S. Huptas, H. C. Geiss, C. Otto and K. G. Parhofer, "Effect of Atorvastatin (10 mg/day) on Glucose Metabolism in Patients with the Metabolic Syndrome,” American Journal of Cardiology, Vol. 98, No. 1, 2006, pp. 66-69. doi:10.1016/j.amjcard.2006.01.055

[16] A. L. Culver, I. S. Ockene, R. Balasubramanian, B. C. Olendzki, D. M. Sepavich, J. Wactawski-Wende, J. E. Manson, Y. Qiao, S. Liu, P. A. Merriam, C. RahillyTierny, F. Thomas, J. S. Berger, J. K. Ockene, J. D. Curb and Y. Ma, "Statin Use and Risk of Diabetes Mellitus in Postmenopausal Women in the Women's Health Initiative," Archives of Internal Medicine, Vol. 172, No. 2, 2012, pp. 144-152. doi:10.1001/archinternmed.2011.625

[17] M. de Lorgeril, P. Salen, J. Abramson, S. Dodin, T. Hamazaki, W. Kostucki, H. Okuyama, B. Pavy and M. Rabeaus, "Cholesterol Lowering, Cardiovascular Diseases, and the Rosuvastatin-JUPITER Controversy: A Critical Reappraisal," Archives of Internal Medicine, Vol. 170, No. 12, 2010, pp. 1032-1036.

doi:10.1001/archinternmed.2010.184

[18] N. Sattar, D. Preiss, H. M. Murray, P. Welsh, B. M. Buckley, A. J. de Craen, S. R. Seshasai, J. J. McMurray, D. J. Freeman, J. W. Jukema, P. W. Macfarlane, C. J. Packard, D. J. Stott, R. G. Westendorp, J. Shepherd, B. R. Davis, S. L. Pressel, R. Marchioli, R. M. Marfisi, A. P. Maggioni, L. Tavazzi, G. Tognoni, J. Kjekshus, T. R. Pedersen, T. J. Cook, A. M. Gotto, M. B. Clearfield, J. R. Downs, H. Nakamura, Y. Ohashi, K. Mizuno, K. K. Ray and I. Ford, "Statins and Risk of Incident Diabetes: A Collaborative Meta-Analysis of Randomised Statin Trials,” Lancet, Vol. 375, No. 9716, 2010, pp. 735-742.

[19] D. Preiss, S. R. Seshasai, P. Welsh, S. A. Murphy, J. E. Ho, D. D. Waters, D. A. DeMicco, P. Barter, C. P. Cannon, M. S. Sabatine, E. Braunwald, J. J. Kastelein, J. A. de Lemos, M. A. Blazing, T. R. Pedersen, M. J. Tikkanen, N. Sattar and K. K. Ray, "Risk of Incident Diabetes with Intensive-Dose Compared With Moderate-Dose Statin Therapy: A Meta-Analysis," Journal of the American Medical Association, Vol. 305, No. 24, 2011, pp. 2556-2564.

[20] K. K. Koh, I. Sakuma and M. J. Quon, "Differential Metabolic Effects of Distinct Statins,” Atherosclerosis, Vol. 2015, No. 1, 2011, pp. 1-8.

[21] M. B. Westover, M. T. Bianchi, M. H. Eckman and S. M. Greenberg, "Statin Use Following Intracerebral Hemorrhage: A Decision Analysis,” Archives of Neurology, Vol. 68, No. 5, 2011, pp. 573-579.

[22] P. Amarenco, O. Benavente, L. B. Goldstein, A. Callahan 3rd, H. Sillesen, M. G. Hennerici, S. Gilbert, A. E. Rudolph, L. Simunovic, J. A. Zivin and K. M. Welch, 
"Stroke Prevention by Aggressive Reduction in Cholesterol Levels Investigators. Results of the Stroke Prevention by Aggressive Reduction in Cholesterol Levels (SPARCL) Trial by Stroke Subtypes,” Stroke, Vol. 40, No. 4, 2009, pp. 1405-1409.

[23] K. K. Ray, S. R. Seshasai, S. Erqou, P. Sever, J. W. Jukema, I. Ford and N. Sattar, "Statins and All-Cause Mortality in High-Risk Primary Prevention: A Meta-Analysis of 11 Randomized Controlled Trials Involving 65,229 Participants," Archives of Internal Medicine, Vol. 170, No. 12, 2010, pp. 1024-1031. doi:10.1001/archinternmed.2010.182

[24] X. Huang, H. Chen, W. C. Miller, R. B. Mailman, J. L. Woodard, P. C. Chen, D. Xiang, R. W. Murrow, Y. Z. Wang and C. Poole, "Lower Low-Density Lipoprotein Cholesterol Levels Are Associated with Parkinson's Disease,” Movement Disorders, Vol. 22, No. 3, 2007, pp. 377-381

[25] C. W. Shults, D. Oakes, K. Kieburtz, M. F. Beal, R. Haas, S. Plumb, J. L. Juncos, J. Nutt, I. Shoulson, J. Carter, K. Kompoliti, J. S. Perlmutter, S. Reich, M. Stern, R. L. Watts, R. Kurlan, E. Molho, M. Harrison, M. Lew and Parkinson Study Group, "Effects of Coenzyme Q10 in Early Parkinson Disease: Evidence of Slowing of the Functional Decline,” Archives of Neurology, Vol. 59, No. 10, 2002, pp. 1541-1550.

[26] A. Lieberman, K. Lyons, J. Levine and R. Myerburg, "Statins, Cholesterol, Co-Enzyme Q10, and Parkinson's Disease,” Parkinsonism \& Related Disorders, Vol. 11, No. 2, 2005, pp. 81-84.

[27] L. Mascetelli, F. Pezzetta and M. R. Goldstein, "Why Statin Therapy May Increase the Risk of Posttransplantation Squamous Cell Carcinoma,” Transplant Immunology, Vol. 23, No. 4, 2010, pp. 224-225. doi:10.1016/j.trim.2010.06.001

[28] J. Kuoppala, A. Lamminpää and E. Pukkala, "Statins and Cancer: A Systematic Review and Meta-Analysis,” European Journal of Cancer, Vol. 44, No. 15, 2008, pp. 2122-2132. doi:10.1016/j.ejca.2008.06.025

[29] H. Rosenberg and D. Allard, "Evidence for Caution: Women and Statin Use Women and Health Protection," Canadian Government White Paper, June 2007.

[30] P. S. Sever, C. L. Chang, A. K. Gupta, A. Whitehouse, N. R. Poulter and ASCOT Investigators, "The Anglo-Scandinavian Cardiac Outcomes Trial: 11-Year Mortality Follow-Up of the Lipid-Lowering Arm in the UK,” European Heart Journal, Vol. 32, No. 20, 2011, pp. 25252532.

[31] C. M. Machan, P. K. Hrynchak and E. L. Irving, “AgeRelated Cataract Is Associated with Type 2 Diabetes and Statin Use,” Optometry \& Vision Science, Vol. 89, No. 8, 2012, pp. 1165-1171.

\section{doi:10.1097/OPX.0b013e3182644cd1}

[32] R. Nakazato, H. Gransar, D. S. Berman, V. Y. Cheng, F. Y. Lin, S. Achenbach, M. Al-Mallah, M. J. Budoff, F. Cademartiri, T. Q. Callister, H. J. Chang, R. C. Cury, K. Chinnaiyan, B. J. W. Chow, A. Delago, M. Hadamitzky, J. Hausleiter, P. Kaufmann, E. Maffei, G. Raff, L. J. Shaw, T. C. Villines, A. Dunning, G. Feuchtner, Y. J. Kim, J. Leipsic and J. K. Mina, "Statins Use and Coronary Artery Plaque Composition: Results from the International Multicenter Confirm Registry,” Atherosclerosis, Vol. 225, No. 1, 2012, pp. 148-153.

[33] P. Raggi, M. Davidson, T. Q. Callister, et al., “Aggressive versus Moderate Lipid-Lowering Therapy in Hypercholesterolemic Postmenopausal Women: Beyond Endorsed Lipid Lowering with EBT Scanning (BELLES)," Circulation, Vol. 112, 2005, pp. 563-571. doi:10.1161/CIRCULATIONAHA.104.512681

[34] A. Schmermund, S. Achenbach, T. Budde, et al., "Effect of Intensive versus Standard Lipid-Lowering Treatment with Atorvastatin on the Progression of Calcified Coronary Atherosclerosis over 12 Months: A Multicenter, Randomized, Double-Blind Trial," Circulation, Vol. 113, 2006, pp. 427-437.

doi:10.1161/CIRCULATIONAHA.105.568147

[35] R. Saremi, P. D. Reaven and G. Bahn, "For the VADT Investigators. Progression of Vascular Calcification Is Increased with Statin Use in the Veterans Affairs Diabetes Trial (VADT),” Diabetes Care, Vol. 35, No. 11, 2012, pp. 2390-2392. doi:10.2337/dc12-0464

[36] J. W. McEvoy, M. J. Blaha, A. P. Defilippis, et al., “Coronary Artery Calcium Progression: An Important Clinical Measurement? A Review of Published Reports,” Journal of the American College of Cardiology, Vol. 56, No. 20, 2010, pp. 1613-1622. doi:10.1016/j.jacc.2010.06.038

[37] J. G. Terry, J. J. Carr, E. O. Kouba, et al., "Effect of Simvastatin $(80 \mathrm{mg})$ on Coronary and Abdominal Aortic Arterial Calcium (From the Coronary Artery Calcification Treatment with Zocor [CATZ] Study)," American Journal of Cardiology, Vol. 99, No. 12, 2007, pp. 1714-1717. doi:10.1016/j.amjcard.2007.01.060

[38] D. Lee and A. Goldberg, "Atrogin1/MAFbx: What Atrophy, Hypertrophy, and Cardiac Failure Have in Common," Circulation Research, Vol. 109, No. 2, 2011, pp. 123-126.

[39] P. J. Barter, M. Caulfield, M. Eriksson, S. M. Grundy, J. J. P. Kastelein, M. Komajda, J. Lopez-Sendon, L. Mosca, J. C. Tardif, D. D. Waters, C. L. Shear, J. H. Revkin, K. A. Buhr, M. R. Fisher, A. R. Tall and B. Brewer, "For the Illuminate Investigators. Effects of Torcetrapib in Patients at High Risk for Coronary Events," The New England Journal of Medicine, Vol. 357, 2007, No. 21, pp. 21092122. 